\title{
Neuroophthalmological management of optic pathway gliomas
}

\author{
ANDREW G. LEE, M.D. \\ Departments of Ophthalmology, Neurology, and Neurosurgery at the University of Iowa Hospitals \\ and Clinics, the H. Stanley Thompson Neuro-ophthalmology Clinic, Iowa City, Iowa
}

\begin{abstract}
$\checkmark$ The growth rate of optic pathway gliomas (OPGs) is unpredictable and quite variable, especially in children with neurofibromatosis Type 1 (NF1). Close neuroophthalmalogical clinical follow-up with serial imaging (magnetic resonance imaging of the brain with and without contrast enhancement) is the recommended initial step in management to establish the growth rate of the lesion in an individual patient. Typically, only symptomatic and/or radiographically growing tumors require treatment, and observation is the accepted first-line option. Although both chemotherapy and radiotherapy can stabilize growth or even decrease the size of tumors, chemotherapy, especially in younger patients, has fewer side effects than radiation therapy (such as secondary tumors, radiation necrosis, and Moyomoya disease) and is generally considered the first-line treatment for progressive lesions in younger patients. The tumor location defines prognosis in OPGs; optic nerve gliomas (ONG) have the lowest rate of complications and death, and optic chiasm and retrochiasmal gliomas the highest. Although the major complication of an OPG is visual loss, hypothalamic involvement can lead to death. Resection is an option for ONGs but is generally reserved for tumors confined to the optic nerve with poor or no vision, or for patients with severe, cosmetically unappealing proptosis, producing severe pain or exposure keratopathy in a blind eye. Resection is generally not an option for intrinsic chiasmal or retrochiasmal OPGs. Extrinsic (exophytic) components can be debulked surgically, and surgery can be performed for hydrocephalus (ventriculoperitoneal shunt placement). The approach to a patient with OPG must be individualized based on tumor location, radiographic or clinical progression, the presence of NF1, and a risk-benefit comparison for treatment. (DOI: 10.3171/FOC-07/11/E1)
\end{abstract}

\section{KEY WORDS • glioma • neurofibromatosis • optic pathway}

$\mathrm{O}$ PTIC pathway gliomas are slow-growing neoplasms that may cause visual or neurological complications and death. They are typically described by location as involving the optic nerve or optic chiasm, and may affect the hypothalamus or third ventricle, producing hydrocephalus. Posterior visual pathway involvement may also occur in patients with OPGs. Dutton ${ }^{30}$ reviewed the literature concerning OPGs through 1994 and summarized the clinical characteristics (Table 1). Lee and Dutton ${ }^{51}$ updated this literature review in 1999. The present study includes selected English language references from the two reviews, and an update from 1999 emphasizing reports on treatment. ${ }^{1-80}$ Optic pathway gliomas are typically seen in children (mean 8.8 years, median 7.0 years), ${ }^{30,51}$ but lateonset de novo OPGs and late progression of preexisting OPGs in children with NF1 have also been reported.52-54 There is no sex predilection for OPG. In children the lesion

Abbreviations used in this paper: $\mathrm{MR}=$ magnetic resonance; $\mathrm{NF} 1$ = neurofibromatosis Type $1 ; \mathrm{OCG}=$ optic chiasm glioma; $\mathrm{ONG}=$ optic nerve glioma; $\mathrm{OPG}=$ optic pathway glioma; $\mathrm{RT}=$ radiation therapy. tends to be low grade and benign, but in adults OPGs tend to be atypical and follow a more aggressive and malignant course. The present study will be confined to the discussion of the typical childhood-onset OPG.

\section{Neurofibromatosis Type 1 and OPG}

About $30 \%$ of patients with OPGs have NF1. There are conflicting reports in the literature over whether NF1 predicts a better prognosis for OPG. Shuper and colleagues ${ }^{72}$ found that NF1 was a favorable prognostic indicator in their series of 21 patients, but others have not confirmed improved survival rates with NF1. Jenkin and associates ${ }^{49}$ demonstrated a "borderline favorable prognosis" $(p=0.06)$ for OPG in patients with NF1. Opocher et al. ${ }^{64}$ performed a systematic literature review of 23 articles and reported three studies with multivariate analysis that supported better progression-free survival for patients with OPG and NF1 compared to those without NF1. Likewise, Listernick et al. ${ }^{52-54,80}$ believe that NF1 provides a better prognosis and that the presence of NF1 might influence decisions on treatment and follow-up. 
TABLE 1

Clinical characteristics of patients with optic pathway gliomas in the study by Dutton, 1994*

\begin{tabular}{lc}
\hline \hline \multicolumn{1}{c}{ Characteristic } & \% of Patients \\
\hline association with NF1 & 29 \\
tumor location & 75 \\
chiasm & 24 \\
optic nerve alone & 1.6 \\
optic disc & 87.5 \\
visual loss at presentation & 35 \\
optic disc edema & 59 \\
optic disc atrophy & \\
proptosis & 94 \\
orbital involvement & 18 \\
chiasmal glioma & \\
ophthalmoplegia & 27 \\
orbital involvement & 21 \\
chiasmal glioma & 23 \\
nystagmus & 26 \\
hypothalamic signs & 28 \\
headache &
\end{tabular}

* Patients had an equal sex distribution and a mean age of 8.8 years (median 7.0 years).

\section{Location of OPGs}

Optic pathway gliomas can affect the optic nerve, optic chiasm, or the retrochiasmal visual pathway. By definition, optic nerve gliomas are confined to the optic nerve and represent $24 \%$ of OPGs, whereas the remaining $76 \%$ of cases involve the optic chiasm. In patients with OCGs, the chiasm alone is affected in $6.6 \%$, the chiasm and optic nerve are both involved in $47.2 \%$, and the chiasm and brain (usually the hypothalamus) in $46.2 \% .^{30}$ In some patients there might also be retrochiasmal (especially of the optic tract) or posterior visual pathway involvement. ${ }^{56}$

\section{Clinical Symptoms and Signs in OPGs}

Visual loss is the main deficit caused by OPGs. The neuroophthalmic presentation varies depending on the involvement of one or both optic nerves (unilateral or bilateral visual loss due to an optic neuropathy), the optic chiasm (bitemporal hemianopsia), or retrochiasmal pathway (hom- onymous hemianopsia). Visual loss is common in patients with OPGs and is present in $87.5 \%$ at diagnosis. ${ }^{30}$ The extent of visual loss is variable and a patient's vision may range from 20/20 to no light perception. The majority of patients $(55 \%)$ have poor visual acuity of worse than 20/ 300 in one (ONG) or both eyes (OCG or bilateral ONG). Optic pathway gliomas tend to be slow-growing tumors and as a result the diagnosis can be delayed, especially in younger children not able to articulate the visual loss. The duration of symptoms prior to the obtaining of neuroimaging studies and an eventual diagnosis of OPG is typically several months to years.

Other presenting symptoms can include diplopia or increasing proptosis and other neuroophthalmical signs in addition to the visual acuity and visual field loss, including pupillary abnormalities (such as relative afferent pupillary defect or sluggishly reactive pupils), optic disc edema $(35 \%)$ or atrophy $(59 \%)$, choroidal folds, proptosis, ophthalmoplegia, or nystagmus (23\%), ${ }^{30}$ and spasmus-nutanslike movements. ${ }^{4}$ Neurological signs and symptoms may also be the result of hypothalamic involvement in patients with precocious puberty ${ }^{50}$ and accelerated linear growth; or the result of hydrocephalus in patients with macrocephaly, headache (28\%), nausea, vomiting, and diplopia. ${ }^{30,51}$ Leptomeningeal involvement is uncommon. ${ }^{17,22}$ Neuroophthalmologic surveillance of patients with OPGs is therefore recommended with age-appropriate evaluations of visual function (such as preferential looking testing, figure matching, Snellen visual acuity, formal visual field testing, color vision testing, and pupillary and dilated fundus examination). ${ }^{42,44,46,47}$

\section{Diagnosis of OPG}

The diagnosis of OPG depends on clinical recognition of an optic nerve or chiasmal lesion followed by appropriate neuroimaging. The presence or absence of NF1 should be established. Orbital and cranial computed tomography scans of OPGs may show fusiform enlargement of the optic nerve, kinking of the optic nerve, or enlargement or enhancement of the optic nerve, chiasm, or retrochiasmal visual pathways. ${ }^{43}$ Magnetic resonance imaging is usually superior for demonstrating these findings in OPGs and also

TABLE 2

Summary of management considerations for OPGs*

- The growth rate of OPGs is unpredictable \& variable, especially in children w/ NF1.

- Clinical serial neuroophthalmic \& radiographic follow-up exams including imaging studies of the brain are recommended for patients w/ OPGs. Observation is the recommended initial management.

- Typically only symptomatic \& clinically or radiographically progressive OPGs require consideration for treatment.

- $\quad$ Although both chemotherapy \& radiotherapy can decrease the size of or stabilize growth of OPGs, chemotherapy causes fewer side effects \& should generally be considered first.

- Tumor location defines prognosis in OPGs. Optic nerve gliomas have the fewest associated complications \& deaths, \& OCGs \& HTGs have the highest.

- The major complication is visual loss; the major cause of death is hypothalamic involvement.

- Resection is an option for ONGs but is generally reserved for patients w/ poor or no vision, severe proptosis that is cosmetically unappealing or producing severe pain in a blind eye.

- Resection is generally not an option for intrinsic chiasmal or retrochiasmal OPGs. Extrinsic or cystic components can be debulked surgically on a case-by-case basis.

- $\quad$ Surgery for shunt placement can be performed to treat hydrocephalus in patients w/ OPGs.

* Summary based on the findings of Dutton, 1994, and Lee \& Dutton, 1999. Abbreviation: HTG = hypothalamic glioma. 
TABLE 3

Summary of progression rates, side effects and complications of treatment, and mortality rates based on two published literature review studies*

- The progression/recurrence rate for OPGs was $\sim 37 \%$, combining tumors in all locations.

- The overall mortality rate was $39 \%$, but individual mortality rates vary based on the specific OPG location. Highest rates were seen in HTGs.

- The ONG progression/recurrence rate is $21.9 \%$. Excision of an ONG can achieve a surgical "cure" w/ < $1 \%$ mortality rate, but will cause complete blindness postoperatively. Excision may be considered in blind eyes w/ severe proptosis or for painful \& blind eyes.

- The overall estimated response rate (stabilization) to chemotherapy for progressive ONGs is $48 \%$. In OCGs managed w/ observation alone, the progression/recurrence rate was $\sim 41 \%$ \& mortality rate was $\sim 29 \%$. The risks associated w/ chemotherapy are uncommon but not trivial and include neutropenia or thrombocytopenia.

- For OCGs treated w/ RT, the progression rate was 41\% and mortality rate was $27 \%$; $50 \%$ of RT-treated patients experienced radiation side effects.

- In HTGs the progression \& mortality rates were both 46\%. In patients treated w/ RT for HTG, the progression rate was $\sim 49 \%$ \& the mortality rate was $\sim 43 \%$.

* Summary based on the findings of Dutton, 1994, and Lee \& Dutton, 1999.

for documenting intracranial involvement (hypothalamic and retrochiasmal involvement and hydrocephalus). In some cases there is a hemorrhagic, cystic, or exophytic (extrinsic) component to the lesion..$^{19}$ Magnetic resonance images are superior to computed tomography scans for defining the extent of intracanalicular or intracranial involvement (in the hypothalamus and along the optic tract for example) and also may be useful in the identification of other intracranial lesions suggestive of NF1..$^{38,401,45}$ In most cases, typical neuroimaging in the appropriate clinical presentation is sufficiently diagnostic to obviate the need for tissue confirmation via biopsy sampling, but some atypical cases still require pathological confirmation. ${ }^{30,51}$

\section{Management of OPG}

Despite extensive literature on the subject, the best management for OPGs remains controversial. ${ }^{30,51}$ The major limitations for all of the studies conducted to date include incomplete or noncomparable data; combined reports from before and after the advent of MR imaging; a lack of histological diagnosis in all cases (especially after the introduction of MR imaging); lack of, short, or poor follow-up; poor documentation of the pretreatment tumor location; lack of or poor documentation of the presence or absence of NF1; small sample sizes, referral, selection, ascertainment, and recall bias; and uncontrolled retrospective data. ${ }^{30,51}$ Despite these limitations, some recommendations can be made. Tables 2 and 3 summarize the key management points. ${ }^{30,51}$

\section{Neuroophthalmic Management Guidelines for OPGs}

In the 1994 and updated 1999 reviews of the literature on OPGs (including 1136 and 1364 cases, respectively) the overall long-term prognosis for visual function $(>11$ years) was good ("stable or improved") in $78 \%$, but poor (worsening vision) in $22 \%$. Likewise, $80 \%$ had stable visual fields over the same period of time..$^{30}$ Unfortunately, the rate of recurrence or clinical or radiographic progression was moderately high at $38-40 \%$, and the overall mortality rate in patients with OPGs was 30-33\%. In their systematic review, Opocher et al. ${ }^{64}$ reported two studies with multivariate analysis supporting tumor site as a prognostic factor (albeit with some methodological limitations). ${ }^{42,44}$ Because the major goal in managing cases of OPG is to preserve vision for as long as possible, initial observation is recommended for all patients harboring OPGs. Continued observation is generally recommended for OPGs that do not progress clinically or radiographically. In addition, some OPGs actually spontaneously regress. ${ }^{55}$ The management of OPGs thus requires an individualized approach, but tumor location is a major factor in the decision making. ${ }^{50,57,58}$

\section{Management of ONG}

In prior literature reviews, stable or improved vision was demonstrated in $91 \%$ of ONGs that were observed rather than treated (114 cases), and recurrence or progression was seen in $21 \%$. The tumor-related mortality rate for ONGs is low (probably $<6 \%$ ) and presumably occurs from intracranial extension. ${ }^{30,51}$ Although there could be progression to the other eye or the optic chiasm from an ONG, many authors believe this to be a theoretical risk only. ${ }^{52-54,62}$

Patients with ONGs treated with either complete or partial excision and then by RT (200 reported cases) suffered vision loss as a complication. ${ }^{30}$ Thus, surgery alone is probably counterproductive in ONG if the goal is to preserve vision. Patients with no useful vision, severe eye-threatening proptosis, or a blind, painful eye might benefit from gross-total resection. In the literature reviews, there were no tumor-related deaths in patients who underwent complete resection of the ONG, but most authors would not recommend resection in a seeing eye. ${ }^{30,51}$

Unlike OPGs confined to the optic nerve alone (ONGs), OCGs are not generally amenable to complete excision without incurring unacceptable complications such as bilateral visual loss. Debulking of the exophytic or cystic component of the OCG can be considered in individual cases (especially in those with rapid progression), but the indications for surgery are not well defined. ${ }^{79}$ However, patients with OCGs or hypothalamic gliomas who develop hydrocephalus may benefit from shunt placement. As in ONGs, the general recommendation for both OCGs and hypothalamic gliomas is initial clinical and radiographic observation for evidence of progression.

Optic pathway gliomas with progressive disease can be treated with RT. 111,12,15,25,32,34,37,39,41,49,66,69 However, RT may 
TABLE 4

Summary of the literature concerning response to chemotherapy in optic pathway gliomas*

\begin{tabular}{|c|c|c|c|}
\hline Authors, Year & Chemotherapy Regimen & Median FU Duration & Response to $\mathrm{Tx}$ \\
\hline Packer et al., 1988 (24) & vinc/AD & 4 yrs & stable disease (14) \\
\hline Petronio et al., 1991 (15) & TPDVL & $67.3 \mathrm{wks}$ & stable disease (3) \\
\hline Packer et al., 1993 (30) & car/vinc & $14 \operatorname{mos}$ & stable disease $(10)$ \\
\hline Janss et al., 1995 (32) & AD/vinc (31), VP16/vinc (1) & $72 \operatorname{mos}$ & stable disease (9) \\
\hline Sutton et al., 1995 (10) & $\mathrm{AD} / \mathrm{vinc}$ & 3 yrs & stable disease (10) \\
\hline Aquino et al., 1999 (12) & car & $38.6 \mathrm{mos}$ & stable disease (6), partial response (4) \\
\hline Mahoney et al., 2000 (50) & car & $18 \mathrm{mos}$ & $39 / 50$ stable or better \\
\hline Silva et al., 2000 (14) & car (8), car \& vinc (4), other (2) & 15 mos to $8 \mathrm{yrs}$ & 5-year progression-free survival $63 \%$ \\
\hline Mitchell et al., 2001 (12) & monthly car & not applicable & stable radiologic disease (9) \\
\hline Gnekow et al., $2004(123) \dagger$ & vinc/car & $22.5 \operatorname{mos}$ & progression-free survival $61 \%$ \\
\hline
\end{tabular}

* All numbers in parentheses are numbers of patients. Abbreviations: AD = actinomycin-D; car = carboplatin; FU = follow-up; TPDVL = 6-thioguonine, procarbazine, dibromodulatol, vincristine, lomustine; $\mathrm{Tx}=$ treatment; vinc $=$ vincristine; $\mathrm{VP} 16=$ etoposide .

$\dagger$ Patients had a median age of 3.7 years.

result in significant complications in children with OPGs, such as cerebrovascular disease, Moyamoya disease, cerebral atrophy, secondary malignancies, mental retardation, cataracts, radiation retinopathy, endocrinopathy, and radiation necrosis of the optic pathways or hypothalamus. ${ }^{11,12,}$ 15,32,63 Although abnormally low intelligence or learning disabilities after RT is relatively common and may be debilitating, the development of secondary tumors after RT can be life threatening. Jenkin et al. ${ }^{49}$ reported that $5(10 \%)$ of 48 patients treated with RT (median follow-up period of 11 years) developed a second malignant tumor (fatal in all cases) compared with the 49 patients who did not receive RT and did not develop subsequent tumors.

Sharif and associates ${ }^{71}$ reviewed 80 NF1-related OPGs treated with and without RT. In this cohort, $9(50 \%)$ of 18 patients with OPGs developed 12 second tumors after RT (in 308 person-years of follow-up) compared with only 8 (20\%) of 40 patients who were not treated with RT who developed 9 tumors in 721 person-years of follow-up. The relative risk of a second nervous system tumor after RT was 3.04 (95\% confidence interval, 1.29-7.15), and the authors concluded that there is a "significantly increased risk" of a second tumor in patients with NF1 who are treated with RT for OPGs. New and emerging RT modalities and techniques such as fractionated stereotactic RT may reduce the risks of RT but have not completely eliminated them. ${ }^{23}$

In previous literature reviews, the visual outcome in patients with OCGs (mean follow-up of 10 years) indicated stable vision in $68 \%$ of patients who received RT compared with $81 \%$ of those who were simply observed. ${ }^{30,51}$ The recurrence or progression rate was $41 \%$ in both the RT-treated group and the observation group, and the mortality rate in both groups was $27 \%$. Many authors believe that although RT may have short-term benefits in delaying OPG progression, it has little influence on final visual outcome or survival. . $^{30,51}$

Chemotherapy is useful for delaying the need for RT in progressive OPGs and has been used with variable success (67-90\% stabilization). ${ }^{62,65,67,70}$ Carboplatin-based regimens such as carboplatin and vincristine have been the most commonly studied, but other regimens (with or without carboplatin) have been reported as well (Table 4). Chemotherapy is considered the first-line therapy advocated by many authors, and has significantly fewer associated complications than RT. The carboplatin regimens also appear to be relatively well tolerated, but neutropenia, thrombocytopenia, and allergic reactions may occur. Although chemotherapy may delay progression or stabilize visual function in patients with progressive OPGs, there remains a significant rate of progression or recurrence after chemotherapy.

\section{Conclusions}

Optic pathway gliomas are typically childhood tumors. The growth rates of OPGs are variable but unpredictable, and their management should be individualized on a caseby-case basis. Close clinical neuroophthalmic follow-up and serial radiography (preferably MR imaging of the brain) are recommended for OPGs. Observation is the recommended initial management. Typically only symptomatic and radiographically progressing OPGs require strong consideration for treatment. Although both chemotherapy and RT can decrease the size or growth of an OPG and stabilize visual loss, chemotherapy, especially in patients younger than 5 years of age, causes fewer side effects than RT and should be considered as a first-line therapy for progressive lesions. Radiation therapy can produce significant neurocognitive and endocrinological complications and carries a significant risk of secondary tumor development, especially in patients with OPGs due to NF1. ${ }^{66}$ Tumor location defines prognosis, as ONGs have the lowest morbidity and mortality followed by OCGs and then hypothalamic glioma. The major symptom of OPG is visual loss, but the major cause of systemic complications or death is typically hypothalamic involvement (causing electrolyte abnormalities) or hydrocephalus. Resection is an option for ONG, but is generally reserved for patients with poor or no vision, patients with cosmetically unappealing severe proptosis, or for ONGs producing severe pain or exposure keratopathy in a blind eye. Resection is generally not an option for intrinsic OCGs, hypothalamic gliomas, or retrochiasmal OPGs. Extrinsic (exophytic or cystic) components can be debulked surgically, but the indications for this treatment are controversial. Future work and emerging therapies such as endoscopic techniques, brachytherapy, and stereotactic fractionated conformal $\mathrm{RT}^{74}$ may improve our strategies for managing cases of OPG. Currently, however, the recommendation remains for case-by-case decision making. 77,78 


\section{Acknowledgment}

This work was supported in part by an unrestricted grant from Research to Prevent Blindness, Inc., New York, New York.

\section{References}

1. Aarabi B, Long DM, Miller NR: Enlarging optic chiasmal glioma with stable visual acuity. Surg Neurol 10:175-177, 1978

2. Addy DP, Hudson FP: Diencephalic syndrome of infantile emaciation. Analysis of literature and report of further 3 cases. Arch Dis Child 47:338-343, 1972

3. Ahn Y, Cho BK, Kim SK, Chung YN, Lee CS, Kim IH, et al: Optic pathway glioma: outcome and prognostic factors in a surgical series. Childs Nerv Syst 22:1136-1142, 2006

4. Albright AL, Sclabassi RJ, Slamovitz TL, Bergman I: Spasmus nutans associated with optic gliomas in infants. J Pediatr 105: 778-780, 1984

5. Alshail E, Rutka JT, Becker LE, Hoffman HJ: Optic chiasmatichypothalamic glioma. Brain Pathol 7:799-806, 1997

6. Alvord EC Jr, Lofton S: Gliomas of the optic nerve or chiasm. Outcome by patients' age, tumor site, and treatment. J Neurosurg 68:85-98, 1988

7. Anderson DR, Spencer WH: Ultrastructural and histochemical observations of optic nerve gliomas. Arch Ophthalmol 83: 324-335, 1970

8. Antony JH, Ouvrier RA, Wise G: Spasmus nutans: a mistaken identity. Arch Neurol 37:373-375, 1980

9. Applegate LJ, Pribram HF: Hematoma of optic nerve glioma-a cause for sudden proptosis. Magnetic resonance imaging findings. J Clin Neuroophthalmol 9:15-19, 1989

10. Aquino VM, Fort DW, Kamen BA: Carboplatin for the treatment of children with newly diagnosed optic chiasm gliomas: a phase II study. J Neurooncol 41:255-259, 1999

11. Bataini JP, Delanian S, Ponvert D: Chiasmal gliomas: results of irradiation management in 57 patients and review of literature. Int J Radiat Oncol Biol Phys 21:615-623, 1991

12. Beyer RA, Pader P, Sobel DF, Flynn FG: Moyamoya pattern of vascular occlusion after radiotherapy for glioma of the optic chiasm. Neurology 36:1173-1178, 1986

13. Bilgiç S, Erbengi A, Tinaztepe B, Onol B: Optic glioma of childhood: clinical, histopathological, and histochemical observations. Br J Ophthalmol 73:832-837, 1989

14. Borit A, Richardson EP Jr: The biological and clinical behavior of pilocytic astrocytomas of the optic pathways. Brain 105: 161-187, 1982

15. Brand WN, Hoover SV: Optic glioma in children. Review of 16 cases given megavoltage radiation therapy. Childs Brain 5: 459-466, 1979

16. Brauner R, Malandry F, Rappaport R, Zucker JM, Kalifa C, Pierre-Kahn A, et al: Growth and endocrine disorders in optic glioma. Eur J Pediatr 149:825-828, 1990

17. Bruggers CS, Friedman HS, Phillips PC, Wiener MD, Hockenberger B, Oakes WJ, et al: Leptomeningeal dissemination of optic pathway gliomas in three children. Am J Ophthalmol 111: 719-723, 1991

18. Bynke H, Kågström E, Tjernström K: Aspects on the treatment of gliomas of the anterior visual pathways. Acta Ophthalmol (Copenh) 55:267-280, 1977

19. Charles NC, Nelson L, Brookner AR, Lieberman N, Breinin GM: Pilocytic astrocytoma of the optic nerve with hemorrhage and extreme cystic degeneration. Am J Ophthalmol 92:691-695, 1981

20. Chutorian AM, Housepian EM, Hilal S: Optic gliomas of multicentric origin with favorable response to radiotherapy. Trans Am Neurol Assoc 101:229-232, 1976

21. Chutorian AM, Schwartz JF, Evans RA, Carter S: Optic gliomas in children. Neurology 14:83-95, 1964

22. Civitello LA, Packer RJ, Rorke LB, Siegel K, Sutton LN, Schut L:
Leptomeningeal dissemination of low grade gliomas in childhood. Neurology 38:562-566, 1988

23. Combs SE, Schulz-Ertner D, Moschos D, Thilmann C, Huber PE, Debus J: Fractionated stereotactic radiotherapy of optic pathway gliomas: tolerance and long-term outcome. Int J Radiat Oncol Biol Phys 62:814-819, 2005

24. Condon JR, Rose FC: Optic nerve glioma. Br J Ophthalmol 51: 703-706, 1967

25. Danoff BF, Kramer S, Thompson N: The radiotherapeutic management of optic nerve gliomas in children. Int J Radial Oncol Biol Phys 6:45-50, 1980

26. Davis PC, Hofman JC Jr, Weidenheim KM: Large hypothalamic and optic chiasm gliomas in infants: difficulties in distinction. AJNR Am J Neuroradiol 5:579-585, 1984

27. Desoretz DE, Blitzer PH, Wang CC, Linggood RM: Management of glioma of the optic nerve and/or chiasm: an analysis of 20 cases. Cancer 45:1467-1471, 1980

28. DeSousa AL, Kalsbeck JE, Mealey J Jr, Ellis FD, Muller J: Optic chiasmatic glioma in children. Am J Ophthalmol 87:376-381, 1979

29. DeSousa AL, Kalsbeck JE, Mealey J Jr, Fitzgerald J: Diencephalic syndrome and its relation to opticochiasmatic glioma: review of twelve cases. Neurosurgery 4:207-209, 1979

30. Dutton JJ: Gliomas of the anterior visual pathway. Surv Ophthalmol 38:427-452, 1994

31. Easley JD, Scharf L, Chou JL, Riccardi VM: Controversy in the management of optic pathway gliomas. 29 patients treated with radiation therapy at Baylor College of Medicine from 1967 through 1987. Neurofibromatosis 1:248-251, 1988

32. Epstein MA, Packer RJ, Rorke LB, Zimmerman RA, Goldwein JW, Sutton LN, et al: Vascular malformation with radiation vasculopathy after treatment of chiasmatic/hypothalamic glioma. Cancer 70:887-893, 1992

33. Flickinger JC, Torres C, Deursch M: Management of low-grade gliomas of the optic nerve and chiasm. Cancer 61:635-642, 1988

34. Furuya Y, Uemura K, Ryu H, Nakajima S, Sato K, Yokoyama T, et al: Optic glioma decreasing in size after irradiation. J Clin Neurol 1:173-175, 1986

35. Glaser JS, Hoyt WF, Corbett J: Visual morbidity with chiasmal glioma. Long-term studies of visual fields in untreated and irradiated cases. Arch Ophthalmol 85:3-12, 1971

36. Gnekow AK, Kortmann RD, Pietsch T, Emser A: Low grade chiasmatic-hypothalamic glioma-carboplatin and vincristine chemotherapy effectively defers radiotherapy within a comprehensive treatment strategy. Report from the multicenter treatment study for children and adolescents with a low grade gliomaHIT-LGG 1996 - of the Society of Pediatric Oncology and Hematology (GPOH). Klin Padiatr 216:331-342, 2004

37. Gould RJ, Hilal SK, Chutorian AM: Efficacy of radiotherapy in optic gliomas. Pediatr Neurol 3:29-32, 1987

38. Haik BG, Saint Louis L, Bierly J, Smith ME, Abramson DA, Ellsworth RM, et al: Magnetic resonance imaging in the evaluation of the optic nerve gliomas. Ophthalmology 94:709-717, 1987

39. Harter DJ, Caderao JB, Leavens ME, Young SE: Radiotherapy in the management of primary gliomas involving the intracranial optic nerves and chaism. Int J Radiat Oncol Biol Phys 4: 681-686, 1978

40. Holman RE, Grimson BS, Drayer BP, Buckley EG, Brennan MW: Magnetic resonance imaging of optic gliomas. Am J Ophthalmol 100:596-601, 1985

41. Horwich A, Bloo HJG: Optic gliomas: radiation therapy and prognosis. Int J Radiat Oncol Biol Phys 11:1067-1079, 1985

42. Hoyt WF, Baghdassarian SA: Optic gliomas of childhood. Natural history and rationale for conservative management. Br J Ophthalmol 53:793-798, 1969

43. Hoyt WF, Fletcher WA, Imes RK: Chiasmal gliomas. Appearance and long-term changes demonstrated by computerized tomography. Prog Exp Tumor Res 30:113-121, 1987

44. Imes RK, Hoyt WF: Childhood chiasmal gliomas: update on the 
fate of patients in the 1969 San Francisco Study. Br J Ophthalmol 70:179-182, 1986

45. Imes RK, Hoyt WF: Magnetic resonance imaging signs of optic nerve gliomas in neurofibromatosis 1. Am J Ophthalmol 111: 729-734, 1991

46. Iraci G, Gerosa M, Tomazzoli L, Pardatscher K, Fiore DL, Javicoli $\mathrm{R}$, et al: Gliomas of the optic nerve and chiasm. A clinical review. Childs Brain 8:326-349, 1981

47. Jahraus CD, Tarbell NJ: Optic pathway gliomas. Pediatr Blood Cancer 46:586-596, 2006

48. Janss AJ, Grundy R, Cnaan A, Savino PJ, Packer RJ, Zackai EH, et al: Optic pathway and hypothalamic/chiasmatic gliomas in children younger than age 5 years with a 6-year follow-up. Cancer 75:1051-1059, 1995

49. Jenkin D, Angyalfi S, Becker L, Berry M, Buncic R, Chan H, et al: Optic glioma in children: surveillance, resection, or irradiation? Int J Radiat Oncol Biol Phys 25:215-225, 1993

50. Laue L, Comite F, Hench K, Loriaux DL, Cutler GB Jr, Pescovitz $\mathrm{OH}$ : Precocious puberty associated with neurofibromatosis and optic gliomas. Treatment with luteinizing hormone releasing hormone analogue. Am J Dis Child 139:1097-1100, 1985

51. Lee AG, Dutton J: A practice pathway for the management of gliomas of the anterior visual pathway: an update and an evidence-based approach. Neuro-Ophthalmol 22:139-155, 1999

52. Listernick R, Charrow J, Greenwald M: Emergence of optic pathway gliomas in children with neurofibromatosis type 1 after normal neuroimaging results. J Pediatr 121:584-587, 1992

53. Listernick R, Charrow J, Greenwald M, Mets M: Natural history of optic pathway tumors in children with neurofibromatosis type 1: a longitudinal study. J Pediatr 125:63-66, 1994

54. Listernick R, Ferner RE, Liu GT, Gutmann DH: Optic pathway gliomas in neurofibromatosis-1: controversies and recommendations. Ann Neurol 61:189-198, 2007

55. Liu GT, Lessell S: Spontaneous visual improvement in chiasmal gliomas. Am J Ophthalmol 114:193-201, 1992

56. Lourie GL, Osborne DR, Kirks DR: Involvement of posterior visual pathways by optic nerve gliomas. Pediatr Radiol 16: 271-274, 1986

57. Lund AM, Skovby F: Optic gliomas in children with neurofibromatosis type 1. Eur J Pediatr 150:835-838, 1991

58. MacFadzean RM, Brewin TB, Doyle D, Grossart K: Glioma of the optic chiasm and its management. Trans Ophthalmol Soc UK 103:199-207, 1983

59. Mahoney DH Jr, Cohen ME, Friedman HS, Kepner JL, Gemer L, Langston JW, et al: Carboplatin is effective therapy for young children with progressive optic pathway tumors: a Pediatric Oncology Group phase II study. Neuro Oncol 2:213-220, 2000

60. McDonnell P, Miller N R: Chiasmatic and hypothalamic extension of optic nerve glioma. Arch Ophthalmol 101:1412-1415, 1983

61. Mitchell AE, Elder JE, Mackey DA, Waters KD, Ashley DM: Visual improvement despite radiologically stable disease after treatment with carboplatin in children with progressive low-grade optic/thalamic gliomas. J Pediatr Hematol Oncol 23:572-577, 2001

62. Moghrabi A, Friedman HS, Burger PC, Tien R, Oakes WJ: Carboplatin treatment of progressive optic pathway gliomas to delay radiotherapy. J Neurosurg 79:223-227, 1993

63. Okuno T, Prensky AL, Gado M: The moyamoya syndrome associated with irradiation of an optic glioma in children: report of two cases and review of the literature. Pediatr Neurol 1:311-316, 1985

64. Opocher E, Kremer LC, Da Dalt L, van de Wetering MD, Viscardi E, Caron HN, et al: Prognostic factors for progression of child- hood optic pathway glioma: a systematic review. Eur J Cancer 42:1807-1816, 2006

65. Packer RJ, Large B, Ater J, Nicholson HS, Allen J, Walker R, et al: Carboplatin and vincristine for recurrent and newly diagnosed low-grade gliomas of childhood. J Clin Oncol 11:850-856, 1993

66. Packer RJ, Savino PJ, Bilaniuk LT, Zimmerman RA, Schatz NJ, Rosenstock JG, et al: Chiasmatic gliomas of childhood. A reappraisal of natural history and effectiveness of cranial irradiation. Childs Brain 10:393-403, 1983

67. Packer RJ, Sutton LN, Bilaniuk LT, Radcliffe J, Rosenstock JG, Siegel KR, et al: Treatment of chiasmatic/hypothalamic gliomas of childhood with chemotherapy: an update. Ann Neurol 23: 79-85, 1988

68. Petronio J, Edward MSB, Prados M, Freyberger S, Rabbitt J, Silver P, et al: Management of chiasmal and hypothalamic gliomas of infants and childhood with chemotherapy. J Neurosurg 74:701-708, 1991

69. Pierce SM, Barnes PD, Loeffler JS, McGinn C, Tarbell NJ: Definitive radiation therapy in the management of symptomatic patients with optic glioma. Survival and long-term effects. Cancer 65:45-52, 1990

70. Rosenstock JG, Packer RJ, Bilaniuk L, Bruce DA, Radcliffe JL, Savino P: Chiasmatic optic glioma treated with chemotherapy. A preliminary report. J Neurosurg 63:862-866, 1985

71. Sharif S, Ferner R, Birch JM, Gillespie JE, Gattamaneni HR, Baser ME, et al: Second primary tumors in neurofibromatosis 1 patients treated for optic glioma: substantial risks after radiotherapy. J Clin Oncol 24:2570-2575, 2006

72. Shuper A, Horev G, Kornreich L, Michowiz S, Weitz R, Zaizov R, et al: Visual pathway glioma: an erratic tumor with therapeutic dilemmas. Arch Dis Child 76:259-263, 1997

73. Silva MM, Goldman S, Keating G, Marymont MA, Kalapurakal J, Tomita T: Optic pathway hypothalamic gliomas in children under three years of age: the role of chemotherapy. Pediatr Neurosurg 33:151-158, 2000

74. Suárez JC, Viano JC, Zunino S, Herrera EJ, Gomez J, Tramunt B, et al: Management of child optic pathway gliomas: new therapeutical option. Childs Nerv Syst 22:679-684, 2006

75. Sutton LN: Visual pathway gliomas of childhood. Contemp Neurosurg 16:1-6, 1994

76. Sutton LN, Molloy PT, Senyak H, Goldwein J, Phillips PL, Rorke $\mathrm{LB}$, et al: Long-term outcome of hypothalamic/chiasmatic astrocytomas in children treated with conservative surgery. J Neurosurg 83:583-589, 1995

77. Sylvester CL, Drohan LA, Sergott RC: Optic-nerve gliomas, chiasmal gliomas and neurofibromatosis type 1. Curr Opin Ophthalmol7:7-11, 2006

78. Weiss L, Sagerman RH, King GA, Chung CT, Dubowy RL: Controversy in the management of optic nerve glioma. Cancer 59: 1000-1004, 1987

79. Wisoff JH, Abbott R, Epstein F: Surgical management of exophytic chiasmatic-hypothalamic tumors of childhood. J Neurosurg 73:661-667, 1990

80. Zeid JL, Charrow J, Sandu M, Goldman S, Listernick R: Orbital optic nerve gliomas in children with neurofibromatosis type 1 . JAAPOS 10:534-539, 2006

Manuscript submitted August 27, 2007.

Accepted September 14, 2007.

Address correspondence to: Andrew G. Lee, M.D., Department of Ophthalmology, University of Iowa Hospitals and Clinics, 200 Hawkins Drive PFP, Iowa City, Iowa 52242. email: Andrew-lee @uiowa.edu. 